\title{
Use of insecticide-impregnated mosquito nets and other impregnated materials for malaria control in the Americas'
}

\author{
R. H. Zimmerman ${ }^{2}$ and J. Voorham ${ }^{3}$
}

\begin{abstract}
This article reviews the current status of the use of insecticide-impregnated mosquito nets and other impregnated materials in the Americas. Studies from Brazil, Colombia, Ecuador, Guatemala, Peru, Suriname, and Venezuela are examined. It is concluded that most studies have suffered from experimental design errors, short duration problems, and/or inadequate measurement of health indicators. The review brings out the great difficulty of conducting scientific studies that attempt to measure the impact of insecticide-treated materials on malaria incidence. In particular, the low incidence of malaria in the Americas, the high prevalences of $P$. vivax and relapsing cases, and the relationship between human activity patterns and the crepuscular biting patterns of certain malaria vectors stand in the way of easy experimental design and execution. The utilization of impregnated mosquito nets or other impregnated materials as a major component of an integrated malaria control program would be premature at this time. However, it is recommended that well-conceived large-scale trials and interventions be considered when they are based on a thorough understanding of the dynamics of malaria transmission in the area of study.
\end{abstract}

The use of impregnated materials has become an important topic in malaria research and control (1-3). There has been considerable effort in Africa and Asia to conduct large-scale mosquito net trials and introduce mosquito nets into the public health service as a component of an integrated malaria control program (4-7). The basic premise behind using insecticide-impregnated materials to control

\footnotetext{
1 A Spanish version of this article will be published in a forthcoming issue of this journal.

2 Pan American Health Organization, Brasília, Brazil. Mailing address: Organização Pan-Americana da Saúde/Organização Mundial da Saúde; Setor de Embaixadas Norte, Lote 19; Brasília, DF 70800-400 Brazil.

3 Pan American Health Organization, Brasília, Brazil.
}

malaria is that they reduce humanvector contact and decrease the number of infective and infected mosquitoes by killing some or most of those that touch the treated material. The same reasoning is used to justify indoor house spraying with insecticides. However, impregnated materials have the advantage that they can be deployed at the local level, lend themselves to community participation efforts, and complement other currently used methods of vector and malaria control.

Sexton (5) reviewed the use of impregnated materials for the control of malaria and its vectors outside the Americas. He concluded that their use could reduce clinical episodes of malaria, parasitemia, the incidence and prevalence of malaria, and malariarelated mortality among children under five years of age. The review related the procedure's vector impact to decreased house entry, changes in feeding and resting behavior, and reduced longevity. A general conclusion of the review was that the use of impregnated bed nets and curtains would increase, especially if ongoing large-scale research in Africa showed a decrease in child mortality. Recent results of two of the ongoing trials in Kenya (6) and Ghana (7) have shown that child survival did improve when impregnated bed nets were used. In addition, the Kenya trial provided the first evidence that use of impregnated bed nets also reduces severe morbidity caused by malaria (6). 
In the Americas, several studies have been conducted using insecticide-impregnated materials to control malaria (8-20). The question now is whether or not enough convincing evidence exists to recommend broad use of impregnated materials in the Americas, or if specific large-scale trials such as those conducted in Africa and Asia should be promoted.

This article reviews the current research on use of impregnated materials in the Americas and recommends the latter course.

\section{STUDIES CONDUCTED IN THE AMERICAS}

\section{Brazil}

Various unpublished trials have been conducted using impregnated curtains made of jute in shelters without walls. One study, done in Utinga (Belém, Pará State) over a 22-week period in 1983-1984, showed a 95\% reduction in anophelines biting inside when only $5 \%$ of the space was not protected and an $80 \%$ reduction when $17 \%$ of the space was not protected. Similar results were recorded for curtains treated with insecticide as compared to curtains without insecticide. The insecticides used, malathion and propoxur, were considered effective against the mosquitoes for six months, according to WHO bioassay tests.

Similar results were obtained from a trial conducted in the Cumaru mining area of Pará State in 1984-1985 using DDT and malathion (unpublished data, PAHO/SUCAM ${ }^{4}$ ).

In Amapá State, studies were conducted in a mining camp named Lourenço in 1986-1987 (8; unpublished data, PAHO/SUCAM). The study was conducted using deltamethrin at a strength of $20 \mathrm{mg}$ of active ingredient (a.i.) per square meter on jute curtains. The malaria incidence was determined by passive and active case detection and blood smear exam-

\footnotetext{
4 SUCAM = Superintendência de Campanhas de Saúde Pública.
}

ination. The mean incidence of Plasmodium falciparum malaria in the general population had decreased significantly one year after introduction of the impregnated curtains (from $40 \%$ to $4 \%, P<0.01)$. At the same time that there was this decrease in malaria incidence at Lourenço, other mining sites in the area did not exhibit decreased malaria incidence.

More recently, Cavalcante (9) has experimented with use of impregnated curtains to surround the unwalled shacks or barracas used by miners. She examined only entomologic factors and used both synthetic fiber cloth (raffia) and jute cloth (sarrapilha). Her results demonstrated that DDT (2 $\mathrm{mg}$ a.i. $/ \mathrm{m}^{2}$ ) and deltamethrin (25 mg a.i. $/ \mathrm{m}^{2}$ ) had a repellent effect for up to 120 days. Mosquito mortality from DDT-treated synthetic fiber curtains dropped from $100 \%$ at the beginning of the experiment to 23\% 240 days later (WHO bioassay tests). The mortality of anophelines exposed to DDTtreated jute dropped from $100 \%$ to $51 \%$ over the same time period. In the case of deltamethrin, the mosquito mortality dropped from $100 \%$ to $84 \%$ with the synthetic-fiber curtains and from $100 \%$ to $56 \%$ with the jute curtains after 240 days. The effects of the insecticides persisted longer on the sides of the huts away from the sun and in areas that were higher up. An additional trial conducted later in Manaus using deltamethrin (25 mg a.i. $/ \mathrm{m}^{2}$ ) to impregnate raffia found that mosquito mortality was still $87 \%$ after 360 days (10).

In the municipality of Costa Marques, Rondônia State, an investigation of impregnated mosquito-net effectiveness was carried out in 1992-1993 (11). This study compared three groups of 20 houses each where cotton bed nets impregnated with deltamethrin (20 mg a.i. $/ \mathrm{m}^{2}$ ), bed nets without insecticide, and no bed nets (a control group) were employed. The treated bed nets were reimpregnated with insecticide after six months. Bed net use during the study was irregular, ranging from $48.3 \%$ to $78.8 \%$. The principal vectors in the area were Anopheles darlingi and An. deaneorum, and the predominant parasite was Plasmodium vivax (present in $63.0 \%$ of the infections). Clinical, parasitologic, and entomologic evaluations were performed bimonthly for one year. The number of mosquitoes recorded by human landing counts inside the houses with impregnated bed nets fluctuated over time, as did mosquito collections made in the houses with untreated nets and in the control houses. No statistical comparison was made of the results obtained in the three groups of houses, but general comparisons showed no observable differences between the groups using treated and untreated nets. Also, standard epidemiologic indicators (malaria prevalence, splenomegaly, and serology) revealed no consistent effect on malaria morbidity by age group. The author suggests that the main factor contributing to the lack of significant differences between the control and the intervention groups was a general decline in malaria incidence throughout the state.

\section{Colombia}

In the region of the San Juan River, along the Pacific Coast of Colombia in the locality of Potedó, a malaria control study was conducted in 1993-1994 with cotton and synthetic bed nets impregnated with lambda-cyhalothrin (10-30 $\mathrm{mg}$ a.i. $/ \mathrm{m}^{2}$ ) as part of a larger malaria control investigation (12). The bed net intervention was conducted in 11 paired localities (11 where treated nets were used and 11 controls). The number of persons residing in the intervention settlements was 1225 before the intervention and 1418 after it. In the control localities there were 1220 inhabitants before the intervention and 1032 after it. Malaria incidence was assessed by household interviews two weeks before the intervention and four months after it. The predominant Plasmodium parasite found was $P$. falciparum (present in $68.5 \%$ of the infections); the major vector was An. neivai. Two intervention localities showed an increased malaria incidence and nine showed a decline four months after the intervention, 
resulting in a change in the average incidence from $6.5 \%$ to $2.3 \%$. Five control localities showed an increased malaria incidence and six showed a decline, resulting in a change in the average incidence from $9.1 \%$ to $7.5 \%$. Only $58.9 \%$ of the houses in the intervention localities had treated bed nets at the end of the study in 1994. Limited bed net use in the intervention localities appears to have been the main drawback of this study (12).

\section{Ecuador}

In the north coastal province of Esmeraldas, an interdisciplinary malaria and leishmaniasis project was conducted jointly in 1989-1990 by the Ecuadorian Ministry of Public Health and the University of Heidelberg, Germany (13). Part of this project consisted of evaluating the effectiveness of cotton $(85 \%)$ and synthetic $(15 \%)$ bed nets treated with permethrin (300 $\mathrm{mg}$ a.i. $/ \mathrm{m}^{2}$ ). Three groups of subjects were compared. One group consisting of 225 families (1 561 persons) received treated bed nets plus additional education about malaria; this group had $80 \%$ coverage during the study period. A second group consisting of $235 \mathrm{fam}$ ilies (1 455 persons) received treated bed nets but no additional education; coverage in this group was $45 \%$. The third group, a control group consisting of 916 families (5 599 persons), received neither treated nets nor additional education. $P$. vivax was present in most $(75.7 \%)$ of the malaria cases detected; the major vector was $A n$. albimanus. There were no significant differences between the intervention and control groups with regard to malaria incidence, as measured by active case detection two weeks before the intervention and eight months afterward. However, eight months after the intervention the more intensive intervention group showed a decrease in malaria incidence of $1.0 \%$ (from $12.7 \%$ to $11.7 \%$ ), while the control group exhibited a $2.2 \%$ increase (from $13.5 \%$ to $15.7 \%$ ).

Several reasons were given for the poor results. One was an increased abundance of anophelines during the intervention year that greatly increased vector-human contact. Another was a suspension of regular indoor house spraying for malaria prevention just before the test, a suspension that may have kept the malaria incidence high among the intervention group and may also have raised the incidence in the control group slightly. It should also be noted that the participants washed their nets frequently, and that the $80 \%$ bed net coverage attained may not have been sufficient.

Another study using cotton and synthetic bed nets impregnated with permethrin (200-300 $\mathrm{mg}$ a.i. $/ \mathrm{m}^{2}$ ) was conducted in Esmeraldas Province in 1993-1994 (12). In the Canton of Bordón, nine paired localities were selected. P. falciparum was present in $85.7 \%$ of the malaria infections detected in these localities; the principal vector was An. albimanus. Despite pairing of the localities, no controls were used. Instead, localities where DDT was used as an indoor house spray were compared with the localities using the impregnated bed nets. The study localities with the treated bed nets had 2093 inhabitants before the intervention and 1806 after it, while the localities where DDT house spraying was employed had 1711 inhabitants before the intervention and 1422 after it. Bed net coverage ranged from $81.8 \%$ to $88.6 \%$ during the trial. The mean incidence of malaria in the nine intervention localities four months before treatment of the bed nets was $21.6 \%$, as compared to $5.3 \%$ four months after the intervention. By comparison, the pre-intervention malaria incidence in the DDT-treated localities averaged $16.4 \%$, while the average post-treatment malaria incidence was $5.8 \%$. Overall, the treated bed nets appeared to lower the malaria incidence; however, without control data this is uncertain.

Another similar study had been conducted in the Canton of Muísne, Esmeraldas Province, in 1991-1992. Seven paired intervention and control localities were selected (12). The population of the former communities was
1225 before the intervention and 1418 after it, while the population of the control communities was 1220 before the intervention and 1032 after it. The predominant vector in the area was An. albimanus, and the predominant parasite (detected in $68.6 \%$ of the malaria infections) was P. falciparum. Bed net coverage increased from $82 \%$ at the start of the study to $96.2 \%$ at the end. The mean malaria incidence decreased from $9.6 \%$ around the start of the intervention to $3.7 \%$ four months post-intervention in the communities using the impregnated bed nets and from $7.9 \%$ to $4.6 \%$ in the control communities. One factor limiting the intervention's success could have been a high rate of $P$. vivax infection (50\%) with poor case detection and presumed overlapping of malaria attacks in the control group (14).

\section{Guatemala}

The only study in the area of Central America and Mexico was conducted in northern Guatemala in 1990-1991 (15, 16). Malaria's incidence and point prevalence were measured throughout the study. Results were compared for separate localities using polyester permethrin-treated nets $(500 \mathrm{mg}$ a.i./ $\mathrm{m}^{2}$ ), untreated nets, and no nets. In two additional localities, 25 houses employed treated nets and 25 houses served as controls. The dominant malaria parasite during the study was $P$. vivax (present in $90 \%$ of the cases) (15), and the principal malaria vectors were An. albimanus and An. vestitipennis (16). Bed net coverage during the trial was $99 \%$.

After 13 months the incidence density (cases per 1000 person-years of observation) was significantly lower in the treated locality (86 cases per 1000 inhabitants) and the untreated netusing locality (106 cases per 1000 inhabitants) than it was in the control locality (200 cases per 1000 inhabitants). Also, the episodes of clinical malaria were fewer among people using treated versus untreated nets, but this difference was not statistically significant. 
The results of the entomologic evaluation were as follows: (1) Fewer anophelines were found resting inside the houses with treated bed nets than were found in the other houses; (2) the average number of mosquitoes collected with human bait in the houses with treated bed nets did not differ significantly from the number collected in this manner at other houses; and (3) twenty times more dead mosquitoes were recovered from the horizontal panels of the treated bed nets than from those of the untreated nets (16). This greater abundance of dead mosquitoes on the treated nets could be an indicator of the treated nets' impact on infected and infective mosquitoes.

\section{Peru}

In the north coastal province of Piura, in the community of San Juan Bautista de Catacaos, an intense epidemiologic study of malaria was conducted in 1991-1993 (17). Part of this study included the testing of pyrethroid-impregnated mosquito nets. Some of the nets were made of cotton, others of synthetic fiber. The insecticide used in the first year of the test was lambda-cyhalothrin (9 $\mathrm{mg}$ a.i. $/ \mathrm{m}^{2}$ ), while that used in the second year was permethrin (550 mg a.i. $/ \mathrm{m}^{2}$ ). Six localities were selected for intervention, and six others served as controls. Only random samples of the study populations (308 residents of the intervention communities and 766 residents of the control communities) were tested for malaria before the intervention. However, the general population (2 693 inhabitants in the intervention communities, 4117 in the control communities) was tested after the intervention. The predominant malaria parasite found (in $99 \%$ of the cases) was $P$. vivax; the malaria vector was An. albimanus. The percentages of the intervention community population using bed nets for personal protection ranged from $62.9 \%$ in the first year to $67.2 \%$ in the second year. In the first year the mean malaria incidence increased in the intervention communities from $19.5 \%$ to $27.4 \%$ and in the control communities from $15.1 \%$ to $30.3 \%$, the increase in the latter being over twice as great. In the second year the mean malaria incidence declined in the intervention communities to $10.5 \%$ and in the control communities to $11.3 \%$. The authors questioned whether the change in insecticide might have had an effect on malaria incidence. The high prevalence of $P$. vivax, the early biting activity of An. albimanus, and the low degree of bed net coverage were the probable reasons why no significant differences were found between the average malaria incidences in the intervention and control communities (14).

A second permethrin-impregnated bed net study was conducted in the Peruvian Amazon, in the Department of Madre de Dios, in 1991-1992 (18). Eighteen paired communities were selected for study, the pre-intervention and post-intervention populations of the intervention communities being 3018 and 2993 respectively, and the pre-intervention and post-intervention populations of the control communities being 4285 and 2716 respectively. Pre-intervention bed net coverage was $90 \%$. At the start of the study, $67.2 \%$ of the nets in the intervention communities were impregnated with permethrin (225-497 $\mathrm{mg}$ a.i. $/ \mathrm{m}^{2}$ ); a second treatment was applied to $42.4 \%$ of the bed nets 2-6 months after the first. $P$. vivax was present in all the detected malaria cases; the most abundant anophelines were $A n$. evansae, $A n$. nuñeztovari, and An. rangeli. The mean malaria incidence in all the intervention communities taken together decreased from $8.3 \%$ before the trial to $3.7 \%$ after the trial, while in the control communities it remained essentially unchanged, rising from $5.4 \%$ before the trial to $5.5 \%$ after it. However, the authors pointed out that significant changes in malaria incidence were only detected in those intervention communities that had a pre-intervention incidence exceeding $10 \%$. In those intervention communities where the pre-intervention malaria incidence was below $10 \%$, no significant change in malaria incidence was found relative to the control communities.

\section{Suriname}

Three studies of treated mosquito nets have been conducted in Suriname. One study published in 1989 examined permethrin-impregnated cotton cloth hammock nets and their effect on mortality among anophelines that entered a hut where these nets were deployed (19). Results obtained from exit trap mosquito collections indicated 58\% mortality among mosquitoes leaving the hut with impregnated nets versus $27 \%$ mortality among those leaving a control hut. Although these results were encouraging, the high control mortality prevented meaningful statistical comparison.

From 1989 to 1991, hammock nets impregnated with permethrin (500 mg a.i. $/ \mathrm{m}^{2}$ ) were tested in all Amerindian villages of southern Suriname. Hammock net coverage was $100 \%$. After 36 months the malaria prevalence decreased from approximately 15-20\% to less than $1 \%{ }^{5}$ This success was attributed to customary cultural use of hammock nets and a low washing frequency of one to four months (J. Voorham, unpublished data).

Voorham (20) suggested that because the Bushnegro inhabitants of Suriname typically wash their bed nets weekly (unlike the Amerindians) the relative effectiveness of treated nets among this population would be low. Therefore, he experimented with lambda-cyhalothrin-impregnated nylon wide-mesh gauze that covered the large openings in the wooden walls of huts. Exit traps and landing counts were used to evaluate the biting activity of anophelines. Results showed that indoor biting declined considerably in experimental huts relative to control huts. As no insecticide activity was recorded after 11 months, a reimpregnation method using brushes was employed. Subsequently, the use of impregnated wide-mesh gauze was introduced into the entire eastern interior region of Suriname, replacing DDT house spraying. The prevalence of $P$. falciparum and P. malariae cases

\footnotetext{
5 Voorham J, personal communication.
} 
(P. vivax did not occur in the study area) was reduced significantly, from $35-40 \%$ to $5-10 \%$. Since the initial good coverage could not be maintained easily, the malaria prevalence went up after one year; nevertheless, the prevalence remained below previous values.

\section{Venezuela}

In 1986 a preliminary trial of treated bed nets was conducted at Las Majadas in Bolivar State. ${ }^{6}$ Las Majadas then had 350 inhabitants, of which 55 adults used bed nets. For the study, 33 of the 55 nets were sprayed with permethrin. Six months later, 22 of the 33 persons who contracted malaria were asked if they had used the impregnated nets. Only one had used an impregnated mosquito net. The investigators concluded that this one person probably contracted malaria outside the area enclosed by the net. This was the first experience with testing bed nets in Venezuela, and the investigators suggested that more effort would be necessary to properly evaluate this approach for malaria control. Since then, one or two small studies have been attempted with inconclusive results; no large-scale trial has been conducted.

\section{CONCLUSIONS}

The highly variable results of the foregoing studies (Table 1) are hard to interpret. Most, except for the Guatemalan study, appear to have suffered from experimental design errors, short duration, and/or inadequate measurement of health indicators (21). The mosquito-net studies conducted in Colombia, Ecuador, and Peru were part of larger epidemiologic and educational projects. They were conducted by the same core group of scientists, and the experimental methods

\footnotetext{
6 Y. Rubio-Palis, Escuela de Malariología y Saneamiento Ambiental Dr. Arnoldo Gabaldón, Maracay, Venezuela. Personal communication.
}

were similar $(12,13,17,18)$. In the course of reporting these studies, the authors discuss their experimental design limitations and the difficulties of conducting bed net studies in the region. In addition, Kroeger et al. (14) reviewed the results of four of these trials and concluded that the main limiting factors were a high prevalence of $P$. vivax, low community bed net coverage, and variable vector biting rates.

In Guatemala, the authors concluded that a larger sample size was needed in order to determine whether treated nets lowered the incidence of malaria more than untreated nets (15). They also concluded that further epidemiologic and sociologic studies were needed to confirm the value of impregnated bed nets for malaria control in northern Guatemala.

Recently, the effectiveness of insecticide-impregnated bed nets in reducing malaria infections was reviewed in a meta-analysis of published results (22). The only study included from the Americas was the Guatemalan trial, and even this study was excluded from the final analysis because too few studies had been carried out in areas of $P$. vivax malaria to permit a metaanalysis. (Where P. vivax malaria is prevalent, case relapses may confound the analysis-22.)

Mosquito net and curtain trials are extremely difficult to perform under ideal conditions, let alone when there are multiple factors directly or indirectly affecting the results that cannot be easily separated. Besides experimental design problems involving such things as randomization, controls, sample size, and systematic monitoring of health indicators, there are other factors related to the disease itself that put any study at risk of being inconclusive. These disease factors include low overall incidence, yearly fluctuations in incidence, low mortality, and a high prevalence of $P$. vivax cases $(30-100 \%)$ in the region. These are the same factors that have impeded the study and success of other intervention strategies in the Americas, including study of malaria vaccines.

In this same vein, there are important entomologic factors that affect the outcome of trials studying the efficiency and efficacy of impregnated mosquito nets or curtains. These include the vectors' biting behavior, seasonal variations in vector abundance, shifts in vector behavior due to insecticides, and vector competence.

If we look at just two factors, human activity patterns and mosquito biting activity, we can get an idea of the difficulty of measuring the effects of interventions with impregnated materials and comparing results between areas. Figure 1 shows measurements of An. darlingi's cumulative biting activity from 7 p.m. to 6 a.m. in Suriname and Mato Grosso, Brazil. It can be seen that depending on the region, the biting activity differs-and therefore the intensity of human-vector contact differs. In Suriname, $88 \%$ of the mosquito biting activity occurs inside houses after 9 p.m. and before 5 a.m., when most of the people are asleep (23). However, in Mato Grosso only $32 \%$ of the biting activity occurs inside houses at these hours (24). Reduced human-vector contact during hours of peak mosquito biting activity may have contributed to the success of the impregnation programs in the Surinamese Amerindian and Bushnegro populations. It is not known, however, whether impregnated mosquito nets would significantly lower the malaria incidence in Mato Grosso, where $68 \%$ of the An. darlingi biting activity occurs when people are not under the nets. The situation is even more complicated when more than one vector is involved and when human activity patterns vary.

An. albimanus was the principal vector involved in the studies conducted in Ecuador $(12,13)$, Peru $(17,18)$, and Guatemala (16). It exhibits crepuscular biting behavior (Figure 2), which means that its principal biting activity occurs when much of the human population is outside and most people are not protected by bed nets. Overall, some $82 \%$ of the An. albimanus in the Peru study areas were found to bite before 11 p.m. and after 5-6 a.m. (17). Even though slightly lower percentages of An. albimanus were collected when people were active outside 
TABLE 1. Summary of malaria control studies ${ }^{\mathrm{a}}$ using insecticide-impregnated materials in the Americas

\begin{tabular}{|c|c|c|c|c|c|c|}
\hline Location & Duration & Insecticide & $\begin{array}{l}\text { Item used } \\
\text { and } \% \\
\text { coverage } \\
\text { attained }\end{array}$ & $\begin{array}{l}\text { Predominant } \\
\text { Plasmodium sp. }\end{array}$ & $\begin{array}{l}\text { Predominant } \\
\text { vector }\end{array}$ & Results $^{b}$ \\
\hline $\begin{array}{l}\text { Brazil: Costa Marques, } \\
\text { 1992-93 }\end{array}$ & 12 months & $\begin{array}{l}\text { Deltamethrin } \\
20 \mathrm{mg} \text { a.i. } / \mathrm{m}^{2}\end{array}$ & $\begin{array}{l}\text { Bed nets, } \\
48.3-78.8 \%\end{array}$ & $\begin{array}{l}63 \% \\
\text { P. vivax }\end{array}$ & $\begin{array}{l}\text { An. darlingi, } \\
\text { An. deaneorum }\end{array}$ & $\begin{array}{l}\text { No difference in malaria } \\
\text { incidence }\end{array}$ \\
\hline $\begin{array}{l}\text { Ecuador: Las Esmeraldas, } \\
\text { 1989-90 }\end{array}$ & 12 months & $\begin{array}{c}\text { Permethrin } \\
300 \mathrm{mg} \text { a.i. } / \mathrm{m}^{2}\end{array}$ & $\begin{array}{l}\text { Bed nets, } \\
45-80 \%\end{array}$ & $\begin{array}{l}75.7 \% \\
\text { P. vivax }\end{array}$ & An. albimanus & $\begin{array}{l}\text { No significant difference } \\
\text { in malaria incidence }\end{array}$ \\
\hline $\begin{array}{l}\text { Ecuador: Las Esmeraldas, } \\
\text { Bordón, 1993-94 }\end{array}$ & 8 months & $\begin{array}{c}\text { Permethrin } \\
\text { 200-300 mg a.i. } / \mathrm{m}^{2}\end{array}$ & $\begin{array}{l}\text { Bed nets, } \\
81.8-88.6 \%\end{array}$ & $\begin{array}{l}\quad 85.7 \% \\
\text { P. falciparum }\end{array}$ & An. albimanus & $\begin{array}{l}\text { No significant difference } \\
\text { in malaria incidence } \\
\text { demonstrated }\end{array}$ \\
\hline $\begin{array}{l}\text { Guatemala: Los Amates, } \\
\text { 1990-91 }\end{array}$ & 13 months & $\begin{array}{c}\text { Permethrin } \\
500 \mathrm{mg} \text { a.i. } / \mathrm{m}^{2}\end{array}$ & $\begin{array}{l}\text { Bed nets, } \\
99.0 \%\end{array}$ & $\begin{array}{l}90 \% \\
\text { P. vivax }\end{array}$ & $\begin{array}{l}\text { An. albimanus, } \\
\text { An. vestitipennis }\end{array}$ & $\begin{array}{l}\text { Malaria incidence } \\
\text { decreased significantly }\end{array}$ \\
\hline $\begin{array}{l}\text { Peru: Piura, Catacaos, } \\
\text { 1992-93 }\end{array}$ & 24 months & $\begin{array}{c}\text { Lambda-cyhalothrin, } \\
9 \text { mg a.i. } / \mathrm{m}^{2}, \text { Year } 1 ; \\
\text { Permethrin, } \\
550 \text { mg a.i. } / \mathrm{m}^{2}, \text { Year } 2\end{array}$ & $\begin{array}{l}\text { Bed nets, } \\
62.9-67.2 \%\end{array}$ & $\begin{array}{l}99 \% \\
\text { P. vivax }\end{array}$ & An. albimanus & $\begin{array}{l}\text { No significant difference } \\
\text { between intervention and } \\
\text { control communities }\end{array}$ \\
\hline $\begin{array}{l}\text { Peru: Madre de Dios, } \\
\text { 1991-92 }\end{array}$ & 8 months & $\begin{array}{c}\text { Permethrin } \\
\text { 225-497 mg a.i. } / \mathrm{m}^{2}\end{array}$ & $\begin{array}{l}\text { Bed nets, } \\
60.8 \%\end{array}$ & $\begin{array}{l}100 \% \\
\text { P. vivax }\end{array}$ & $\begin{array}{l}\text { An. evansae, } \\
\text { An. nuñeztovari, } \\
\text { An. rangeli }\end{array}$ & $\begin{array}{l}\text { Malaria decreased in } \\
\text { localities with over } 10 \% \\
\text { incidence }\end{array}$ \\
\hline Suriname: 1989-91 & 36 months & $\begin{array}{c}\text { Permethrin } \\
500 \mathrm{mg} \text { a.i. } / \mathrm{m}^{2}\end{array}$ & $\begin{array}{l}\text { Hammock nets, } \\
100 \%\end{array}$ & $\begin{array}{l}\text { Predominantly } \\
\text { P. falciparum }\end{array}$ & An. darlingi & $\begin{array}{l}\text { Decrease in malaria } \\
\text { incidence }\end{array}$ \\
\hline
\end{tabular}

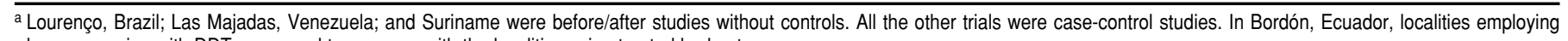
house spraying with DDT were used to compare with the localities using treated bed nets.

${ }^{\text {b }}$ See text for specific results and Kroeger et al. (14) for more details on the studies conducted in Muísne, Potedó, Catacaos, and Madre de Dios.

houses in Ecuador (13), this pattern of biting activity alone could have had a significant negative impact on the results of these trials. In conclusion, the overlap of anopheline and human activity during hours when people are not protected by the mosquito nets could significantly influence the outcome of insecticide-impregnated mosquito net or curtain trials. Of course, if infective females tend to bite later in the night and noninfective females tend to bite earlier, this influence could be reduced (25).

Data on human factors such as the population's level of socioeconomic development, patterns of economic activity, gender, age composition, malaria immunity, cultural practices, and migration patterns also constitute essential a priori information needed for the design and implementation of treated mosquito net or curtain trials.

\section{RECOMMENDATIONS}

It would be premature to use insecticide-impregnated mosquito nets or other materials as a major component of an integrated malaria control program in the Americas at this time.
However, the information currently available is sufficient to support a recommendation for well-conceived, large-scale trials at the community or regional level. These studies should be based on a thorough understanding of the dynamics of malaria transmission in the areas involved.

Specifically, the recommendations of this review are as follows:

- Promote a large-scale trial using impregnated raffia in "stable" mining areas of Brazil. The entomologic data collected by Cavalcante (9) and Figueirdo (10), and malaria case 
FIGURE 1. Cumulative biting activity of An. darlingi inside houses in Suriname (23) and Mato Grosso, Brazil (24)

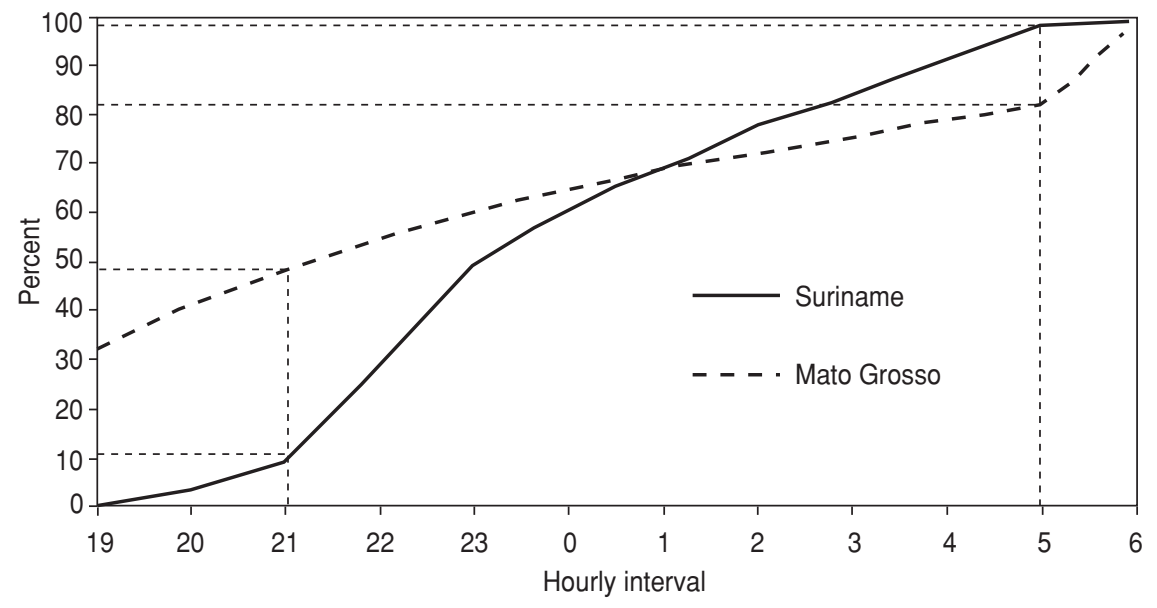

data from the gold mines of Lourenço, support this idea. No doubt such work would need to be supplemented with targeted clinical treatment. In addition, a flexible management system must be designed that would ensure the integrity of the intervention trial and, if it proves successful, provide the groundwork for its future integration into the regional health services.

- Implement a large-scale trial using impregnated mosquito nets in rural northern Guatemala. In preparation

FIGURE 2. Cumulative biting activity of An. albimanus inside houses in Catacaos, Peru (17)

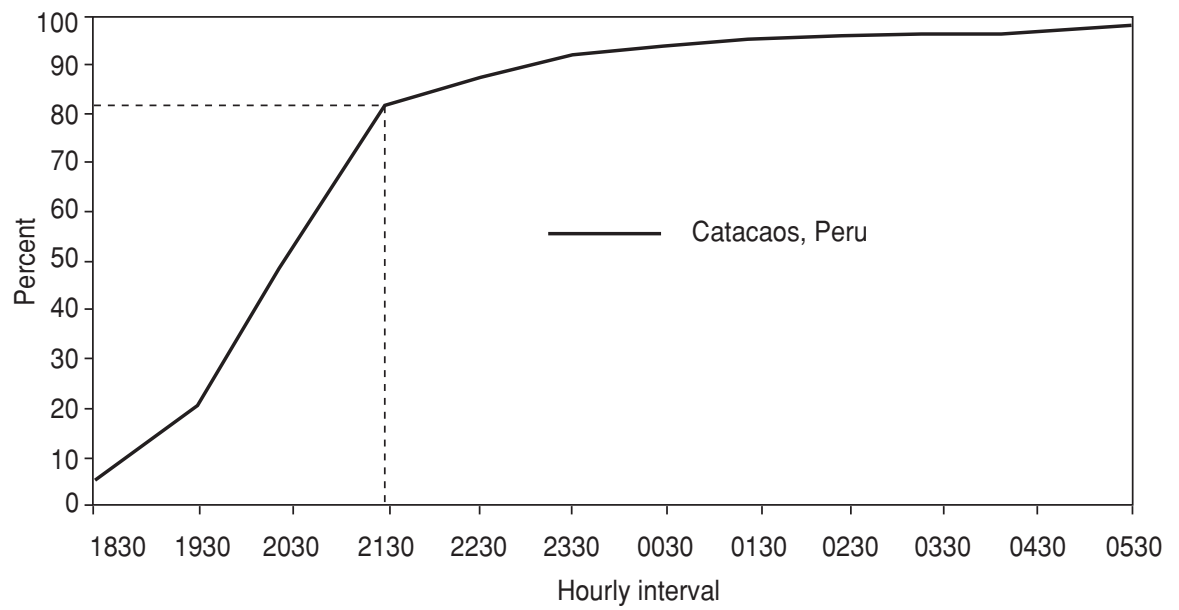

enced the trials' outcomes. These trials did not sufficiently meet the evaluation criteria presented by Bermejo and Veeken (21), nor did they consider the overlap of vector and human activities. A thorough review of the epidemiologic data collected by these studies needs to be made and a better understanding of the malaria transmission dynamics involved needs to be obtained before conducting other large-scale trials in these areas.

- Region-wide interventions using appropriate health indicators for special populations such as the Surinamese Amerindians (impregnated hammock nets) and Bushnegros (impregnated wide-mesh gauze) are warranted.

- With indigenous groups like the Yanomami Indians, questions regarding decreasing immunity and whether a vector control measure such as use of treated mosquito nets or curtains can be sustained need to be seriously considered before conducting a trial. In many cases the principal question is not whether the method works but whether it would be sustainable.

None of this should be taken to indicate that further experimentation in other regions or alternatives such as impregnated screens and curtains are not warranted. For example, the feasibility of using impregnated wide-mesh gauze in stable agricultural colonization areas and of using impregnated hammocks in areas with highly mobile populations should be evaluated.

Equally important, regional guidelines need to be established for impregnated mosquito net and curtain trials in the Americas. The guidelines should be based on a sound knowledge of vector and human activity, disease incidence, cultural practices, and method sustainability. This information needs to be reviewed before a project is implemented or impregnated materials are recommended as a major alternative for malaria control in the Americas. 


\section{REFERENCES}

1. World Health Organization. Aplicación de la estratégia mundial de lucha contra el Paludismo. Geneva: WHO; 1993. (Technical report series, 839).

2. Lengeler C, Lines JD, Cattani J, Feilden R, Zimicki S, Savigny D. Promoting operational research on insecticide-treated netting: a joint TDR/IDRC initiative and call for research proposals. Trop Med Int Health 1996;1: 273-276.

3. United Nations Development Program, World Bank, World Health Organization. TDR news. Switzerland: WHO; 1996 (No. 50, June 1996).

4. Greenwood BM, Baker JR. A malaria control trial using insecticide-treated bed nets and targeted chemoprophylaxis in a rural area of the Gambia, West Africa. Trans $R$ Soc Trop Med Hyg 1993;87(Suppl 2):1-60.

5. Sexton JD. Impregnated bed nets for malaria control: biological success and social responsibility. Am J Trop Med Hyg 1994;50(suppl): 72-81.

6. Nevill CG, Some ES, Mung'ala VO, et al. Insecticide-treated bed nets reduce mortality and severe morbidity from malaria among children on the Kenyan coast. Trop Med Int Health 1996;1:139-146.

7. Binka FN, Kubaje A, Adjuik M, et al. Impact of permethrin impregnated bed nets on child mortality in Kassena-Nankana district, Ghana: a randomized controlled trial. Trop Med Int Health 1996;1:147-154.

8. Xavier PA, Lima JENS. O uso de cortinas impregnadas com deltametrina no control da malária em garimpos no Território Federal do Amapá: nota prévia, 1986. Rev Bras Malariol Doencas Trop 1986;38:137-139.

9. Cavalcante ETS. Avaliação da deltrametrina para o controle da malaria em areas de garimpos [master's thesis in biological sciences]. Manaus,
Brazil: Instituto Nacional de Pesquisas da Amazônia; 1993.

10. Figueirdo RMP. Controle da malaria: poder residual da deltametrina observado em diferente tipos de paredes [master's thesis in biological sciences]. Manaus, Brazil: Instituto Nacional de Pesquisas da Amazônia; 1996.

11. Santos JB. Estudo sobre o uso de mosquiteiros impregnados com deltametrina em una área endêmica de malária da Amazônia Brasileira [postgraduate thesis]. Brasília: Federal University of Minas Gerais; 1995.

12. Kroeger A, Mancheno M, Pesse K. Métodos para mejorar el control de la malaria en Ecuador y Colombia. Cayambe, Ecuador: Abya-Yala; 1995.

13. Kroeger A, Mancheno M, Ruiz W, Estrella E. Malaria y leishmaniasis cutanea en Ecuador: un estudio interdisciplinario; aspectos históricos, epidemiológicos, antropológicos, entomológicos y métodos de control. Quito: Abya-Yala; 1991.

14. Kroeger A, Mancheno M, Alarcón J, Pesse K. Insecticide-impregnated bed nets for malaria control: varying experiences from Ecuador, Colombia, and Peru concerning acceptability and effectiveness. Am J Trop Med Hyg 1995; 53:313-323.

15. Richards FO, Klein RE, Zea Flores R, et al. Permethrin-impregnated bed nets for malaria control in northern Guatemala: epidemiological impact and community acceptance. Am J Trop Med Hyg 1993:49:410-418.

16. Richards FO, Zea Flores R, Sexton JD, et al. Effects of permethrin-impregnated bed nets on malaria vectors of northern Guatemala. Bull Pan Am Health Organ 1994;28:112-121.

17. Pesse K, Castro C. Control de la malaria en la comunidad campesina San Juan Bautista de Catacaos. Report; 1995.

18. Kroeger A, Alarcón J. Malaria en Ecuador y Peru y estrategias alternativas de control. Quito: Abya-Yala; 1993.
19. Rozendaal JA, Voorham J, Van Hoof JPM, Oostburg BFJ. Efficacy of mosquito nets treated with permethrin in Suriname. Med Vet Entomol 1989;3:353-365.

20. Voorham J. The use of impregnated widemesh gauze covering wall openings in huts as a vector control method in Suriname. Rev Saude Publica (São Paulo) 1997;31:9-14.

21. Bermejo A, Veeken H. Insecticide-impregnated bed nets for malaria control: a review of the field trials. Bull World Health Organ 1992;70:293-296.

22. Choi HW, Breman JG, Teutsch SM, Liu S, Hightower AW, Sexton JD. The effectiveness of insecticide-impregnated bed nets in reducing cases of malaria infection: a meta-analysis of published results. Am J Trop Med Hyg 1995:52:377-382.

23. Rozendaal JA, Van Hoof JPM, Voorham J, Oostburg BFJ. Behavioral responses of Anopheles darlingi in Suriname to DDT residues on house walls. I Am Mosq Control Assoc 1989;5:339-350.

24. Charlwood JD, Wilkes TJ. Studies on the age composition of samples of Anopheles darlingi Root (Diptera: Culicidae) in Brazil. Bull Entomol Res 1979;69:337-342.

25. Bockarie MJ, Alexander N, Bockaire F, Ibam E, Barnish G, Alpers M. The late biting habit of parous Anopheles mosquitoes and pre-bedtime exposure of humans to infective female mosquitos. Trans $R$ Soc Trop Med Hyg 1996;90:23-25.

Manuscript received on 13 February 1996. Revised version accepted for publication on 17 October 1996.

RESUMEN En este artículo se revisa el uso actual en las Américas de mosquiteros y otros materiales impregnados con insecticida. Se examinan diversos estudios efectuados en el Brasil, Colombia, Ecuador, Guatemala, Perú, Suriname y Venezuela y se llega a la conclusión de que en su mayor parte estos estudios adolecen de graves deficiencias de diseño, problemas de excesiva brevedad, o de una medición inadecuada de los indicadores de salud. La revisión resalta la gran dificultad de llevar a cabo estudios que buscan medir el impacto de los materiales tratados con insecticidas sobre la incidencia de malaria. En particular, la baja incidencia de malaria en las Américas, las altas prevalencias de Plasmodium vivax y de casos recurrentes y la relación entre los patrones de actividad de los seres humanos y los hábitos de picadura crepusculares de los mosquitos impiden hacer experimentos de fácil diseño y ejecución. Por ahora sería prematuro usar mosquiteros $u$ otros materiales impregnados como componentes principales de un programa integral para el control de la malaria. No obstante, se recomienda que se considere llevar a cabo ensayos bien diseñados a gran escala siempre que se basen en un conocimiento profundo de la dinámica de la transmisión de la malaria en la zona del estudio. 